\title{
Projection of future pharmacy service fees using the dispensing claims in hospital and clinic outpatient pharmacies: national health insurance database between 2006 and 2012
}

Dongmun Ha, Inmyung Song, Eui-Kyung Lee* and Ju-Young Shin *iD

\begin{abstract}
Background: Predicting pharmacy service fees is crucial to sustain the health insurance budget and maintain pharmacy management. However, there is no evidence on how to predict pharmacy service fees at the population level. This study compares the status of pharmacy services and constructs regression model to project annual pharmacy service fees in Korea.

Methods: We conducted a time-series analysis by using sample data from the national health insurance database from 2006 and 2012. To reflect the latest trend, we categorized pharmacies into general hospital, special hospital, and clinic outpatient pharmacies based on the major source of service fees, using a 1\% sample of the 2012 data. We estimated the daily number of prescriptions, pharmacy service fees, and drugs costs according to these three types of pharmacy services. To forecast pharmacy service fees, a regression model was constructed to estimate annual fees in the following year (2013). The dependent variable was pharmacy service fees and the independent variables were the number of prescriptions and service fees per pharmacy, ratio of patients ( $\geq 65$ years), conversion factor, change of policy, and types of pharmacy services.

Results: Among the 21,283 pharmacies identified, 5.0\% (1064), 4.6\% (974), and 77.5\% (16,340) were general hospital, special hospital, and clinic outpatient pharmacies, respectively, in 2012. General hospital pharmacies showed a higher daily number of prescriptions (111.9), higher pharmacy service fees $(\$ 25,546,342)$, and higher annual drugs costs $(\$ 215,728,000)$ per pharmacy than any other pharmacy $(p<0.05)$. The regression model to project found the ratio of patients aged 65 years and older and the conversion factor to be associated with an increase in pharmacy service fees. It also estimated the future rate of increase in pharmacy service fees to be between $3.1 \%$ and $7.8 \%$.

Conclusions: General hospital outpatient pharmacies spent more on annual pharmacy service fees than any other type of pharmacy. The forecast of annual pharmacy service fees in Korea was similar to that of Australia, but not that of the United Kingdom.
\end{abstract}

Keywords: Pharmacy service fee, Drugs cost, Hospital outpatient pharmacy, Clinical outpatient pharmacy, Prediction model

* Correspondence: ekyung@skku.edu; shin.jy@skku.edu

School of Pharmacy, Sungkyunkwan University, 2066 Seobu-ro, Jangan-gu,

Suwon 16419, South Korea 


\section{Background}

The accurate prediction of future medical expenditure can inform policy debates and decision making regarding healthcare resource allocation [1, 2]. Likewise, predicting pharmacy spending, a major factor of national health financing, is essential for budget planning [3]. Forecasting pharmacy service fees, in particular, can be important to sustain the health insurance budget from the payer's perspective while maintaining pharmacy management. Several studies have used statistical modelling approaches based on pharmacy insurance claims data to predict annual healthcare costs in the United States and Canada [4, 5]. Similarly, future healthcare costs including drugs costs in the European Union have been estimated according to various scenarios based on demography, health status, and income [6]. Despite the plethora of research, however, no evidence exists on how to predict pharmacy service fees at the population level.

The changing healthcare environment in Korea makes it difficult to forecast the annual budget for pharmacy service fees and therefore determine dispensing fees for the following year through negotiations between the payer and pharmacist association [7, 8]. From the payer's perspective, a more predictable reimbursement system for pharmacy service fees should be established to stabilize the health insurance budget [9]. From the pharmacist's perspective, an adequate payment mechanism for dispensing services is needed based on a prediction model for pharmacy service fees [10].

Models that forecast healthcare costs commonly rely on a combination of factors including demographics (typically age and sex), diagnoses, and prescription drug utilization data [11]. In particular, developing a model to project pharmacy service fees should be preceded by an analysis of pharmacy services by pharmacy characteristics to consider the various factors influencing such fees. No prediction model of pharmacy service fees has thus far been developed in Korea. Based on the foregoing, this study compares the status of pharmacy services and projects annual pharmacy service fees by evaluating a model for forecasting based on pharmacies' insurance claims data.

\section{Methods}

\section{Database}

This study used the national health insurance database of all insurance enrolees and medical aid beneficiaries in Korea [12]. We extracted a 1\% sample of all pharmacies' insurance claims data in 2012 through stratified systematic sampling and classified the data based on a pharmacy and a prescription for a descriptive analysis on dispensing status. We constructed the dataset to project pharmacy service fees by extracting dispensing data of all pharmacies every year from 2006 to 2012 from the nationwide health insurance claims database. The dataset was composed of time-series cross-section data that gathered according to the flow of time by quarter.

\section{Classification of pharmacies}

To analyse differences in pharmacy service fees, pharmacies were classified based on the type of medical institution that issues over $80 \%$ of the pharmacy's prescriptions: general hospital outpatient pharmacy [13], special hospital outpatient pharmacy [13], clinic outpatient pharmacy, and others. For example, if general hospitals issued over $80 \%$ of all prescriptions dispensed by a pharmacy, the pharmacy was classified as a general hospital outpatient pharmacy. A pharmacy was categorized as 'others' if no single type of medical institution makes up more than $80 \%$ of its prescriptions. Based on the grouping, three dummy variables were constructed for the regression analysis.

\section{Construction model to project pharmacy service fees}

We constructed a model to project pharmacy service fees which comprises the following variables through a factor analysis associated with changes in annual pharmacy service fees: the number of prescriptions per pharmacy, the average dispensing days of prescriptions per pharmacy, the proportion of patients 65 years and older, a conversion factor, change of policy, and pharmacy type. The conversion factor is an index that applies every year to the dispensing fee agreement between the government and pharmacist association [14]. Change of policy represents whether the government changed the dispensing fee control policy or not; a dummy variable was constructed (no change $=0$, change $=1$ ).

\section{Four scenarios to project fees in 2013}

To project pharmacy service fees in 2013, we assumed four scenarios. Scenarios 1 and 2 applied the average increase rate of annual pharmacy service fees in the past 7 years (2006-2012) and 3 years (2010-2012), respectively. Scenarios 3 and 4 applied the maximum and minimum values, respectively, for the rate of increase in the number of prescriptions in 2006-2012.

\section{Statistical analysis}

By using the 2012 data, we performed a descriptive analysis to describe the differences in pharmacy services across pharmacy types. We analysed the average number of pharmacists, number of prescriptions, annual pharmacy service fees per pharmacy, and average drugs costs per prescription by pharmacy type for examining cost changes in pharmacy service fees.

By using the time-series cross-section data, we conducted a regression analysis to test the determinants of annual pharmacy service fees per pharmacy per quarter 
and to analyse changes in annual pharmacy service fees. The independent variables included the number of prescriptions per pharmacy, average dispensing days of prescriptions per pharmacy, proportion of patients aged 65 years and older, conversion factor, change of policy, and pharmacy type. The amounts of pharmacy service fees forecasted for 2013 were compared among the aforementioned four scenarios.

All statistical analyses were performed by using the SAS statistical application program (Version 9.4, SAS Institute Inc., Cary, NC, USA). The approval of the Institutional Review Board for this study with the general population was waived under Article 16 of the Rule of the Bioethics and Safety Act in Korea [15].

\section{Results}

\section{Dispensing status by pharmacy type}

Of the 21,283 pharmacies identified, 5.0\% (1064), 4.6\% (974), and $77.5 \%(16,340)$ were general hospital, special hospital, and clinic outpatient pharmacies, respectively, in 2012. The average number of pharmacists per pharmacy was 1.36, with the largest number (2.39) being in general hospital outpatient pharmacies. Clinic outpatient pharmacies dispensed the largest number of prescriptions $(n=$ 3,869,364, 80.2\%). General hospital outpatient pharmacies had a higher average daily number of prescriptions (111.9), annual dispensing fees $(\$ 25,546,342)$, and annual drugs costs $(\$ 215,728,000)$ than any other pharmacy. Pharmacy service fees (\$7.2), average dispensing days (35.2), and average drugs costs $(\$ 60.6)$ were higher for general hospital outpatient pharmacies than for any other pharmacy (Table 1).

\section{Regression model to project pharmacy service fees per pharmacy per quarter}

The time-series cross-section data analysis estimated that the quarterly pharmacy service fees per pharmacy increased by $\$ 4.7$ for one additional prescription per pharmacy. Pharmacy service fees increased by $\$ 307.3$ for one additional dispensing day per prescription and by $\$ 1082.3$ for a $1 \%$ increase in the proportion of patients aged 65 years and older in the same period. Pharmacy service fees increased by $\$ 494.8$ for one additional point of the conversion factor and decreased by $\$ 956.1$ for a change of policy. Compared with clinic outpatient pharmacies, the fees of general hospital and special hospital outpatient pharmacies increased by $\$ 6028$ and $\$ 1140.0$, respectively, while those of other pharmacies decreased by $\$ 184.1$ (Table 2).

\section{Projection of pharmacy service fees in 2013 according to the four scenarios}

The pharmacy service fees of all pharmacies in 2013 were forecasted to be $\$ 2587.4$ million (Scenario 1), $\$ 2565.8$ million (Scenario 2), \$2663.5 million (Scenario 3), and $\$ 2547.0$ million (Scenario 4) (Table 3). Compared with 2012, the rate of increase in the pharmacy service fees of all pharmacies in 2013 was estimated to be between 3.1\% (Scenario 4) and 7.8\% (Scenario 3) (Fig. 1).

Table 1 Characteristics of pharmacies by type of medical institution in 2012

\begin{tabular}{|c|c|c|c|c|c|c|}
\hline \multicolumn{2}{|l|}{ Category } & $\begin{array}{l}\text { All } \\
\text { pharmacies }\end{array}$ & $\begin{array}{l}\text { General hospital } \\
\text { outpatient pharmacy }\end{array}$ & $\begin{array}{l}\text { Special hospital } \\
\text { outpatient pharmacy }^{\text {d }}\end{array}$ & $\begin{array}{l}\text { Clinic outpatient } \\
\text { pharmacy }\end{array}$ & Others $^{f}$ \\
\hline \multicolumn{2}{|c|}{ Number of pharmacies, n (\%) } & $21,283(100.0)$ & $1064(5.0)$ & $974(4.6 \%)$ & $16,502(77.5)$ & $2743(12.9)$ \\
\hline \multicolumn{2}{|c|}{ Average number of pharmacists $\pm S D^{b}$} & $1.36 \pm 0.78$ & $2.39 \pm 1.67$ & $1.46 \pm 0.87$ & $1.32 \pm 0.66$ & $1.21 \pm 0.57$ \\
\hline \multicolumn{2}{|c|}{ Number of prescriptions, n (\%) } & $4,824,860(100.0)$ & $378,512(7.8)$ & $256,292(5.3)$ & $3,869,364(80.2)$ & $320,692(6.6)$ \\
\hline \multirow[t]{3}{*}{ Per pharmacy } & $\begin{array}{l}\text { Daily average number of } \\
\text { prescriptions } 100 \pm S D^{b}\end{array}$ & $75.6 \pm 70.9$ & $118.6 \pm 99.2$ & $87.7 \pm 93.1$ & $78.6 \pm 67.1$ & $32.0 \pm 54.3$ \\
\hline & $\begin{array}{l}\text { Pharmacy service fees } \\
\text { per year } 100 \pm S D \text { a b }\end{array}$ & $\begin{array}{l}115,936.7 \pm \\
113,175.9\end{array}$ & $255,463.4 \pm 226,645.2$ & $137,114.8 \pm 135,937.0$ & $\begin{array}{l}114,829.4 \pm \\
95,924.6\end{array}$ & $\begin{array}{l}63,655.3 \pm \\
85,875.8\end{array}$ \\
\hline & $\begin{array}{l}\text { Drugs costs per year } \\
100 \pm \mathrm{SD}^{\mathrm{a} b}\end{array}$ & $\begin{array}{l}343,518.2 \pm \\
761,571.8\end{array}$ & $\begin{array}{l}2,157,280.0 \pm \\
2,588,749.4\end{array}$ & $396,526.1 \pm 400,011.9$ & $\begin{array}{l}244,839.5 \pm \\
246,262.2\end{array}$ & $\begin{array}{l}214,662.6 \pm \\
360,265.4\end{array}$ \\
\hline \multirow[t]{4}{*}{ Per prescription } & Pharmacy service fees $\pm S D^{a b}$ & $5.1 \pm 8.8$ & $7.2 \pm 9.1$ & $5.2 \pm 8.9$ & $4.9 \pm 6.5$ & $5.4 \pm 10.1$ \\
\hline & $\begin{array}{l}\text { Average number of prescription } \\
\text { drugs } \pm S D^{b}\end{array}$ & $3.77 \pm 3.58$ & $3.48 \pm 3.59$ & $3.77 \pm 3.76$ & $3.82 \pm 3.55$ & $3.55 \pm 3.91$ \\
\hline & Average dispensing days $\pm \mathrm{SD}^{\mathrm{b}}$ & $11.4 \pm 12.3$ & $35.2 \pm 30.7$ & $10.9 \pm 12.4$ & $8.8 \pm 10.2$ & $14.3 \pm 18.5$ \\
\hline & Average drugs costs $\pm S D^{a b}$ & $15.2 \pm 16.6$ & $60.6 \pm 70.1$ & $15.1 \pm 16.7$ & $10.4 \pm 12.4$ & $18.4 \pm 20.1$ \\
\hline
\end{tabular}

${ }^{a}$ Costs in Korean won were converted into US\$ by using the conversion rate of 1200 won/US\$

bStandard deviation

'Pharmacy that obtained more than $80 \%$ of prescriptions from general hospitals

${ }^{d}$ Pharmacy that obtained more than $80 \%$ of prescriptions from special hospitals

epharmacy that obtained more than $80 \%$ of prescriptions from clinics

fPharmacy that was not $c$, $d$, or e 
Table 2 Factor analysis for projection using time-series cross-section data on pharmacy service fees per pharmacy per quarter

\begin{tabular}{|c|c|c|c|c|c|c|}
\hline Category & Coefficient $^{\mathrm{a}}$ & $\mathrm{SD}^{\mathrm{b}}$ & $\mathrm{t}$ & $95 \% \mathrm{Cl}$ & & $p$-value \\
\hline Number of prescriptions per pharmacy per quarter & 4.7 & 0.002 & 2.229 & 4.667 & 4.674 & $<0.001$ \\
\hline Average dispensing days of prescriptions per pharmacy per quarter & 307.3 & 1.467 & 0.175 & 304.4 & 310.2 & $<0.001$ \\
\hline Ratio of patients aged 65 years and older & 1082.3 & 70.193 & 0.013 & 944.8 & 1219.9 & $<0.001$ \\
\hline Conversion factor & 494.8 & 2.056 & 0.201 & 490.7 & 498.8 & $<0.001$ \\
\hline Change of policy & -956.1 & 11.767 & -0.068 & -979.2 & -933.1 & $<0.001$ \\
\hline \multicolumn{7}{|l|}{ Hospital type } \\
\hline General hospital outpatient pharmacy $^{c}$ & 6028.2 & 56.402 & 0.089 & 5917.6 & 6138.7 & $<0.001$ \\
\hline Special hospital outpatient pharmacy ${ }^{d}$ & 1140.0 & 39.156 & 0.024 & 1063.2 & 1216.7 & $<0.001$ \\
\hline Clinic outpatient pharmacy e & -1494.5 & 101.889 & -0.012 & -1694.2 & -1294.8 & $<0.001$ \\
\hline Other ${ }^{f}$ & -184.1 & 18.888 & -0.008 & -221.2 & -147.1 & $<0.001$ \\
\hline Constant & $-34,916.7$ & 125.224 & -0.232 & $-35,166.7$ & $-34,666.7$ & $<0.001$ \\
\hline
\end{tabular}

${ }^{a}$ Costs in Korean won were converted into US\$ by using the conversion rate of 1200 won/US\$

bStandard deviation

'Pharmacy that obtained more than $80 \%$ of prescriptions from general hospitals

dPharmacy that obtained more than $80 \%$ of prescriptions from special hospitals

epharmacy that obtained more than $80 \%$ of prescriptions from clinics

fPharmacy that was not $c$, d, or e

\section{Discussion}

We developed a model to project pharmacy service fees per pharmacy per quarter by identifying the factors associated with these fees and by including forecasted values for the variables. Time-series cross-section data were analysed to determine the factors that influence pharmacy service fees, using the health insurance claims data submitted by all pharmacies between 2006 and 2012.

The ratio of pharmacy was the highest for clinical hospital outpatient pharmacies among all pharmacies in 2012. While general hospital outpatient pharmacies that had higher pharmacy service fees, average dispensing days, and average drugs costs per prescription had higher annual pharmacy service fees $(\$ 25,546,342)$ and annual drugs costs $(\$ 215,728,000)$ per pharmacy than any other pharmacy.

The rate of increase in the pharmacy service fees of all pharmacies between 2012 and 2013 was projected to be between 3.1\% (Scenario 4) and 7.8\% (Scenario 3). This finding is consistent with previous reports in Korea [16] and Australia [17] but not with those in the United Kingdom [18]. The average increase rate of annual pharmacy service fees was $5.4 \%$ within this range (3.1-7.8\%) between 2005 and 2011 in Korea [16]. The increase rate of prescription volumes covered by the Pharmaceutical Benefits Scheme and Repatriation Pharmaceutical Benefits Scheme of Australia was projected to be $3.4-3.9 \%$ between 2016 and 2020 in sixth Community Pharmacy Agreement between the Commonwealth of Australia and the Pharmacy Guild of Australia despite methodological discrepancies [17, 19]. By contrast, the United Kingdom's Community Pharmacy Contractual Framework funding package for 2016-2017 was reduced by about 4\% compared with 2015-2016 [18]. In the United Kingdom, dispensing fee remuneration for prescriptions comprised the dispensing fees (essential and advanced services) and

Table 3 Pharmacy service fees of the next year (2013), using the regression model for projection

\begin{tabular}{|c|c|c|c|c|}
\hline Category & $\begin{array}{l}\text { Pharmacy service fees for } \\
\text { a quarter }{ }^{a, c}\end{array}$ & $\begin{array}{l}\text { Pharmacy service fees } \\
\text { in } 2013^{a, b}, d\end{array}$ & $\begin{array}{l}\text { Pharmacy service fees in } \\
2012^{a, b}, \mathrm{~d}\end{array}$ & $\begin{array}{l}\text { Year-on-year increase } \\
\text { rate }{ }^{\mathrm{e}} \%\end{array}$ \\
\hline Scenario $1^{f}$ & $31,744.4$ & 2587.4 & 2470.8 & 4.7 \\
\hline Scenario $2^{\mathrm{g}}$ & $31,643.8$ & 2565.8 & 2470.8 & 3.8 \\
\hline Scenario $3^{h}$ & $32,678.1$ & 2663.5 & 2470.8 & 7.8 \\
\hline Scenario $4^{i}$ & $31,248.2$ & 2547.0 & 2470.8 & 3.1 \\
\hline
\end{tabular}

${ }^{a}$ Costs in Korean won were converted into US\$ by using the conversion rate of 1200 won/US\$

${ }^{\mathrm{b}}$ Million US\$

' Pharmacy service fees per pharmacy

d Pharmacy service fees of all pharmacies

${ }^{e}$ Increase rate of the prediction value of 2013 on 2012

${ }^{f}$ Applied the average increase rate of annual pharmacy service fees in 2006-2012

${ }^{9}$ Applied the average increase rate of annual pharmacy service fees in 2010-2012

${ }^{\mathrm{h}}$ Applied the maximum number of prescriptions in 2006-2012

Applied the minimum number of prescriptions in 2010-2012 


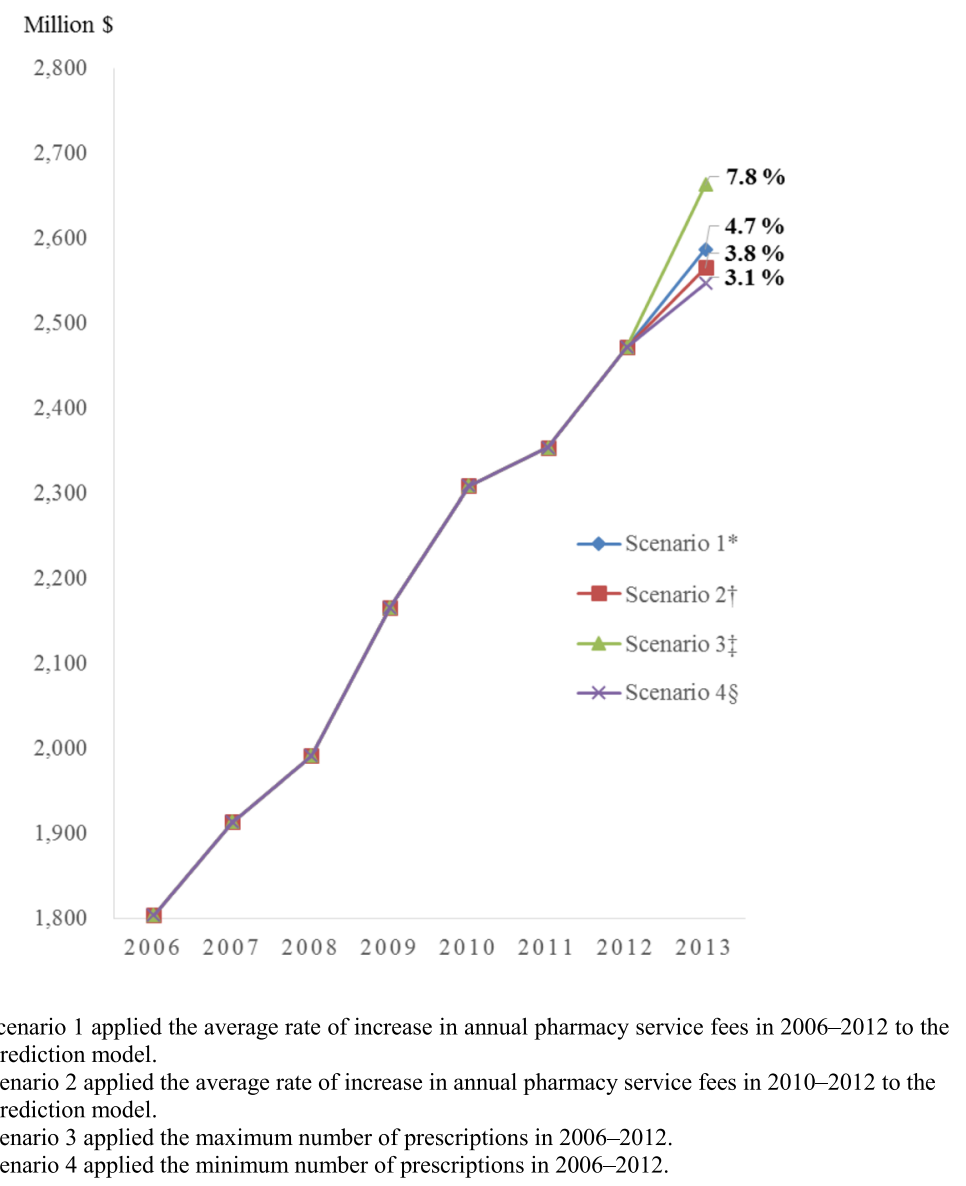

Fig. 1 Pharmacy service fees in 2013 estimated by the prediction model

retained margins determined by using the margins survey [20]. The change of dispensing fee remuneration was due to a reduction in the retained margins by discounting drugs prices because dispensing fees (essential and advanced services) have remained steady every year [21]. On the contrary, no research has thus far predicted dispensing fees in the United States, which does not have a universal public healthcare system [19]. Only the results of a professional dispensing fee analysis for Medicare and Medicaid by state have been revealed [22].

Pharmacy service fees are a function of the price factor (i.e. conversion index) and the quantity factor (i.e. number of prescriptions dispensed) [23]. The conversion index established during fee negotiations between the payer and service providers (i.e. the Korean Pharmacist Association) every May is applicable to the model to project. As the number of prescriptions dispensed is dependent on the number of prescriptions and number of dispensing days per prescription, it is necessary to predict the number of prescriptions dispensed more precisely than the price factor. Pharmacy service fees are associated with a number of factors such as socioeconomic status, individual pharmacy characteristics, and time effects. As the time series data model takes into account individual pharmacy characteristics and time effects, it is regarded as suitable for analysing the factors influencing pharmacy service fees.

As the application of the model for forecasting may yield different results depending on the monitoring period and socioeconomic changes that influence demand for medical services, a mechanism to adjust for these factors is needed. For example, the length of a monitoring period needs to be established by consensus between the payer and service providers. In addition, it is necessary to accurately measure the variables for the longer-term management of dispensing fees. To accurately predict the number of prescriptions dispensed that have the greatest impact on dispensing fees, a mechanism to predict those factors influencing demand for medical services (e.g. population aging, economic development) should be developed in advance.

There was a huge difference in pharmacy service compensation systems between Korea and Australia. Pharmacists are compensated for dispensing services only without pharmacy margins for purchased drugs in Korea, whereas pharmacy service fees include dispensing 
fees and the pharmacy mark-up in Australia. In Australia, dispensing fee remuneration for prescriptions is composed of dispensing fees and administration, handling, and infrastructure fees (replaces the pharmacy margin) [24]. The latter were introduced to replace the previous pharmacy mark-up and delink remuneration from the price of a medicine to allow changes to pricing policy that will not have a significant impact on pharmacy remuneration in the sixth CPA on 1 July 2015 [25].

In Australia, pharmacy service fees were set by consensus between the government and pharmacist association every 5 years based on the future five-year prediction [26]. The management range was $95.0-105.0 \%$ of the predicted dispensing between 2006 and 2010 [27]. In the United Kingdom, pharmacy service fees are also determined by annual negotiations between the government and pharmacist association; the compensation for annual pharmacy services includes drug margins [28]. By adopting the Australian model, the payer (i.e. the National Health Insurance Service) and service providers (i.e. the Korean Pharmacist Association) would be able to predict pharmacy service fees in the following year by mutual consensus, and set a management range at the level that enables both parties to share the risk. If the forecasted amount deviates from the actual amount beyond the management range, considerations could be given during fee negotiations in the subsequent year, such as the adjustment of the conversion index.

We showed that general hospital outpatient pharmacies received higher pharmacy service fees than clinic outpatient pharmacies, suggesting that these hospitals issued a greater number of prescriptions. This finding is consistent with that of a previous study [29]. The number of prescriptions dispensed is dependent on physicians' prescribing activity. Therefore, a methodology that analyses the treatment behaviour of the departments that issue prescriptions should be developed to project annual dispensing fees more accurately.

Whereas previous studies developed a projection model of pharmacy service fees based on the rate of change for each variable by using claims data such as diagnoses and medications and validated projection models of pharmacy service fee by comparing $\mathrm{R}^{2}$ values of the models $[3,11,30]$, the projection model developed in this study is effective for validating the differences in projected and observed pharmacy service fees. Pharmacy service fees in Korea include fees for service provided by the pharmacy and pharmacist but not drug margin. The pharmacy service fees vary according to the type of medical institution the patient uses. For example, a prescription issued by a bigger institution such as general hospital has a greater number of prescribed days, resulting in greater pharmacy service fees. Therefore, to examine cost changes as in the existing studies, we analyzed pharmacy service fees per prescription. To analyze changes in service fees, we projected future pharmacy service fees according to the type of pharmacy which was based on the source of service fees. In validation tests between 2009 and 2012 (results not shown), these differences were estimated to be $-2.5 \%$ to $3.8 \%$. Drug management fees were reduced considerably in $2011(-2.5 \%)$ and the number of prescriptions dispensed decreased due to the economic recession [31]. These changes may have underestimated the projected values for $2010-2012$ as well as the rate of increase in dispensing fees in 2013 compared with the scenarios that applied data from the preceding 7 years.

Our study has several limitations. First, the pharmacies included in our analysis may not be representative of all community pharmacies in Korea. The number of prescriptions dispensed at pharmacies near general hospitals was lower than the national average. Follow-up research using a nationally representative sample may thus be beneficial for the effective management of the health insurance budget. In addition, it was difficult to accurately classify pharmacies; pharmacy types may therefore have been misclassified.

\section{Conclusions}

We showed that general hospital outpatient pharmacies received more annual pharmacy service fees than any other pharmacy because of their higher daily average number of prescriptions per pharmacy. Our findings suggest that future pharmacy service fees can be managed by using a regression model, which can serve as a useful tool when negotiating dispensing fees between the payer and pharmacist association. The change in the projection of annual pharmacy service fees in Korea is similar to that in Australia but not that in the United Kingdom.

Abbreviations

CPA: Community pharmacy agreement; SD: Standard deviation

Acknowledgements

No sources of funding were used in the preparation of this study.

\section{Funding}

Not applicable.

\section{Availability of data and materials}

The data that support the findings of this study are available from the national health insurance database but restrictions apply to the availability of these data, which were used under license for the current study, and so are not publicly available.

\section{Authors' contributions}

$\mathrm{DH}, \mathrm{EKL}$ and JYS designed the study and research concept. IS acquired and arranged the data. Analysis and interpretation of data were performed by $\mathrm{DH}$ and EKL. DH undertook the literature review and drafted the initial manuscript and JYS confirmed the manuscript. All authors read and approved the final manuscript. The authors of this manuscript take responsibility for the integrity of the data and the accuracy of the data analysis. 


\section{Ethics approval and consent to participate}

The approval of the Institutional Review Board for this study with the general population was waived under Article 16 of the Rule of the Bioethics and Safety Act in Korea.

\section{Consent for publication}

Not applicable.

\section{Competing interests}

The authors declare that they have no competing interests.

\section{Publisher's Note}

Springer Nature remains neutral with regard to jurisdictional claims in published maps and institutional affiliations.

Received: 2 February 2018 Accepted: 27 March 2018

Published online: 03 May 2018

\section{References}

1. Huber CA, Schneeweiss S, Signorell A, Reich O. Improved prediction of medical expenditures and health care utilization using an updated chronic disease score and claims data. J Clin Epidemiol. 2013;66(10):1118-27.

2. Xesfingi S, Vozikis A, Pollalis Y. Citizens' preferences on healthcare expenditure allocation: evidence from Greece. Health Expect. 2016;19(6):1265-76.

3. Calderon-Larranaga A, Abrams C, Poblador-Plou B, Weiner JP, Prados-Torres A. Applying diagnosis and pharmacy-based risk models to predict pharmacy use in Aragon, Spain: the impact of a local calibration. BMC Health Serv Res. 2010;10:22.

4. Powers CA, Meyer CM, Roebuck MC, Vaziri B. Predictive modeling of total healthcare costs using pharmacy claims data: a comparison of alternative econometric cost modeling techniques. Med Care. 2005;43(11):1065-72.

5. Canada. IM. Private drug plan cost forecast (2016-2018) research provided by quintiles IMS for innovative medicines Canada. 2016.

6. Projecting future health care expenditure at European level: drivers, methodology and main result. Economic Paper. 2010.

7. Park II-Su, Dong-Hun L. A study on long-turm of finalcial prediction of national health insurance National Health Insurance Service. 2010.

8. Hye-Min P. The finalcial estimation of national health insurnace using sample cohort database. Osong: National Health Insurance Service; 2015.

9. Haaywood A, Llewelyn V, Robertson S, Mylrea M, Glass B. Dose administration aids: pharmacists' role in improving patient care. Australas Med J. 2011;4(4):183-9.

10. Jonathan Anscombe, Michael Thomas, Jonathan Pilmley. The future of community pharmacy in England ATKearney. 2012.

11. Zhao Y, Ash AS, Ellis RP, Ayanian JZ, Pope GC, Bowen B, et al. Predicting pharmacy costs and other medical costs using diagnoses and drug claims. Med Care. 2005:43(1):34-43.

12. Lee J-Y. Construction of an appropriate sampling design and a sample database using the National Health Information Database. Seoul: National Health Insurance Service; 2012.

13. College of Nursing, University of Mosul. Management and leadship. 2013.

14. Hyun-Woong S, Jung-U S, Byung-Wook J, Sul-Lip H, Na-Keom Y, Bo-Ram S. A study on conversion index according to type of medical institution. Osong: The Korea Institute for Health and Social Affairs; 2012.

15. Ministry of Health and Welfare. Article 16 of the rule of the bioethics and safety act. 2012.

16. Chelim Cheong S-EC, Lee H, Kim J. Variations in pharmacy payment of Korea national health insurance and a new taxonomy of community pharmacies. Yakhak Hoeji. 2013;57(1):63-9.

17. Sixth Community Pharmacy Agreement. Australian Government \& the Pharmacy Guild of Australia. 2015

18. Community Pharmacy in $2016 / 2017$ and Beyond. Pharmaceutical Services Negotiating Committee. 2016.

19. Remuneration and Regulation of Community Pharmacy. Deloitte access economics. 2016.

20. An Annual Survey of 120 Community Pharmacies is Undertaken to Verify the Purchase Prices and Quantities of Medicines. Community Pharmacy Contractual Framework. 2016

21. The Community Pharmacy Contractual Framework and the Retained Medicine Margin. National Audit Office 2016
22. Professional Dispensing Fee Analysis for Medicaid Members - Pharmacy Survey Report. The Ohio Department of Medicaid. 2016.

23. Prepared for the Maryland Department of Health and Mental Hygiene Baltimore M. Pharmacy Dispensing Cost Analysis for the State of Maryland. 2011.

24. Dooley M. Pharmacy remuneration and regulation review. Collingwood Victoria: The Society of Hospital Pharmacists of Australia; 2016.

25. Review of Pharmacy Remuneration and Regulation Discussion Paper. Australian Government. 2016.

26. Fifth Community Pharmacy Agreement. Australian Government \& The Pharmacy Guild of Australia. 2010.

27. Compilation of the Fourth Community Pharmacy Agreement between the Commonwealth of Australia and the Pharmacy Guild of Australia. The Pharmacy Guild of Australia. 2010.

28. Funding Settlement of Community Pharmacy in 2012/2013. Pharmacy Services Negotiating Committee. 2012.

29. Hye Kyung Park CIK, Eom TH, Kim YS, Rho YS, Jeong GH, et al. Analysis of financial performance and its factors of community pharmacies in Korea: after the introduction of the separation of drug prescription and dispensing policy. Yakhak Hoeji. 2008;52(6):507-13.

30. Kuo RN, Lai MS. Comparison of Rx-defined morbidity groups and diagnosisbased risk adjusters for predicting healthcare costs in Taiwan. BMC Health Ser Res. 2010;17(10):126.

31. Health Insurance Statistical Data 2012. Ministry of Health and Welfare. 2013.

\section{Submit your next manuscript to BioMed Central and we will help you at every step:}

- We accept pre-submission inquiries

- Our selector tool helps you to find the most relevant journal

- We provide round the clock customer support

- Convenient online submission

- Thorough peer review

- Inclusion in PubMed and all major indexing services

- Maximum visibility for your research

Submit your manuscript at www.biomedcentral.com/submit
Biomed Central 